CLINICAL STUDY

\title{
Glucagon-like peptide-1 receptor agonists in type 2 diabetes: a meta-analysis of randomized clinical trials
}

\author{
Matteo Monami, Niccolò Marchionni and Edoardo Mannucci \\ Unit of Geriatric Medicine, Department of Critical Care Medicine, University of Florence and Azienda Ospedaliera Careggi, Florence, Italy \\ (Correspondence should be addressed to E Mannucci who is now at Section of Geriatric Cardiology, Department of Cardiovascular Medicine, Azienda \\ Ospedaliero-Universitaria Careggi, Via delle Oblate 4, 50141 Florence, Italy; Email: edoardo.mannucci@unifi.it)
}

\begin{abstract}
Objective: The role of glucagon-like peptide-1 (GLP-1) receptor agonists in the treatment of type 2 diabetes is debated; many recent trials, which were not included in previous meta-analyses, could add relevant information.

Design and methods: All available randomized controlled trials (RCTs), either published or unpublished, performed in type 2 diabetic patients with GLP-1 receptor agonists (exenatide and liraglutide), with a duration $>12$ weeks were meta-analysed for HbAlc, body mass index, hypoglycaemia and other adverse events.

Results and conclusions: A total of 21 RCTs (six of which unpublished), enrolling 5429 and 3053 patients (with GLP-1 receptor agonists and active comparator or placebo respectively), was retrieved and included in the analysis. GLP-1 receptor agonists determine a significant improvement of $\mathrm{HbA} 1 \mathrm{c}$ in comparison with placebo $(-1.0(-1.1,-0.8), P<0.001)$, with a low risk of hypoglycaemia. There is no evidence of increased cardiovascular risk with the use of GLP-1 receptor agonists. GLP-1 receptor agonists, which induce weight loss, are associated with gastrointestinal side effects. GLP-1 receptor agonists are effective in reducing $\mathrm{HbAlc}$ and postprandial glucose. In patients failing to sulphonylureas and/or metformin, GLP-1 receptor agonists are similarly effective as insulin. Available data suggest that the efficacy and tolerability of the novel agent, liraglutide, which is adequate for oncea-day administration, are comparable with those of exenatide bis in die.
\end{abstract}

European Journal of Endocrinology 160 909-917

\section{Introduction}

The glucagon-like peptide-1 (GLP-1) receptor agonist exenatide has recently been introduced in the treatment of type 2 diabetic patients inadequately controlled with metformin and/or sulphonylureas $(1,2)$. Other drugs of the same class, such as liraglutide (3), are presently under development, and will soon be available in many countries.

The role of those new drugs in the treatment of type 2 diabetes is debated. The Consensus algorithm of the American Diabetes Association (ADA) and the European Association for the Study of Diabetes (EASD) (4) suggests to limit the use of GLP-1 receptor agonists only to some specific cases, without considering those agents in the mainstream of the algorithm. The reasons for this exclusion are their perceived limited efficacy on HbA1c in comparison with other agents, their poorly defined safety profile, and their cost (4).

Efficacy and safety need to be assessed through a comprehensive revision of presently available clinical trials. Some detailed reviews of published studies are available $(5,6)$; furthermore, only one meta-analysis has been performed (7). However, presently available meta-analyses include only published studies, without any attempt at retrieving data from completed and publicly disclosed, although not formally published, clinical trials. Since very few studies on liraglutide have been published in extensive form to date (3, 8-10), presently available meta-analysis do not provide comprehensive information on the clinical profile of this agent.

The aim of the present study is to offer a comprehensive and updated synthesis of all available clinical data on safety and efficacy of GLP-1 receptor agonists.

\section{Materials and methods}

A meta-analysis was performed including all randomized clinical trials, either with a cross-over or a parallel series design, enrolling patients with type 2 diabetes, with a duration of at least 12 weeks, comparing GLP-1 receptor agonists with placebo or other active drugs. Trials with a shorter duration were excluded, due to the fact that they could not yield relevant information on 
HbA1c, which had been chosen as the principal outcome variable. The QUOROM checklist and flow diagram were used to present abstract, introduction, methods, results and discussion sections.

A Medline search for all articles in English, using the keywords 'exenatide' or 'liraglutide' was performed on November 25th, 2008. Randomized clinical trials were then selected. The identification of relevant abstracts, the selection of studies based on the criteria described above, and the subsequent data extraction were performed independently by two of the authors (E M, $\mathrm{M} \mathrm{M}$ ), and conflicts resolved by the third investigator (N M). The quality of trials was assessed using some items of the scale proposed by Jadad et al. (11). A further search was performed on EMBASE for randomized clinical trials on humans, in English, up to September 1st, 2008, using the keyword 'liraglutide' or 'exenatide', and on Cochrane database, on December 31st, 2008, with the same keywords and with no further limits.

Completed but still unpublished trials were identified through a search of www.clinicaltrials.gov website. Results of those trials were retrieved, if available, on www.novonordisk-trials.com or www.clinicalstudyresults.org; a manual search of abstracts from the last (2008) annual congresses of the ADA and of the EASD was performed, in order to retrieve information on results of unpublished trials (www.easd.org and http:// professional.diabetes.org/CongressReports_List.aspx). For unpublished and published trials which were not exhaustively disclosed, an attempt was made (through e-mail) to contact principal investigators in order to retrieve missing data.

The principal outcome was the effect of GLP-1 receptor agonists, compared with other hypoglycaemic agents or placebo, on $\mathrm{HbAlc}$ at the end of the trial. Secondary outcomes included body mass index (BMI) at the end of the trial. Furthermore, data on the incidence of severe or any hypoglycaemia (number of patients with at least one event) and several adverse events were extracted. The following adverse events were considered: nausea, vomiting and diarrhoea. Furthermore, cases of pancreatitis, angioedema and cardiovascular events (defined as myocardial infarction, angina pectoris, coronary artery revascularization, chronic heart failure, stroke and arteriopathy of lower limbs) reported as serious or severe adverse events were considered, together with death for any cause.

Separate analyses were performed for trials with different GLP-1 receptor agonists, whenever possible.

Heterogeneity was calculated for placebo- and active comparator-controlled trials separately, using the $\mathrm{I}^{2}$ statistics. Weighted mean differences were calculated for $\mathrm{HbA1c}$ and BMI and a random-effects model was used for the meta-analysis. Mantel-Haenszel odds ratio with 95\% confidence interval (MH-OR) was calculated for hypoglycaemia, and the adverse events defined above, using a random-effects model. Publication/disclosure bias was estimated separately for placebo-controlled trials and studies versus active comparators, using the Begg and Mazumdar rank correlation test; Kendall's tau without continuity correction, and one-sided $P$, were calculated. Although the risk of bias due to defects of conduct of randomized trial has been reported to be low for studies investigating the effect of drugs on objective outcomes (12), separate analysis was performed on placebo-controlled trials in order to verify the possible bias associated with inadequate allocation concealment or randomization procedure. All those analyses were performed using comprehensive meta-analysis version 2, Biostat, (Englewood, NJ, USA) and SPSS 16.0. Interaction was assessed using the method described by Altman and Bland (13). The statistical power of the meta-analysis to detect a clinically relevant difference (at least $0.5 \%$ ) in $\mathrm{HbAlc}$ for placebo-controlled and active-comparator trials was assessed, with the method described by Thorlund (14). The bias associated with accumulation of data was explored by calculating weighted mean reduction of $\mathrm{HbAlc}$ and $z$ values separately for trials published before 2005, 2006, 2007, 2008 and 2009 (15).

\section{Results}

The Medline and EMBASE search provided 599 and 43 randomized clinical trials; all the articles retrieved on EMBASE had already been identified through Medline.

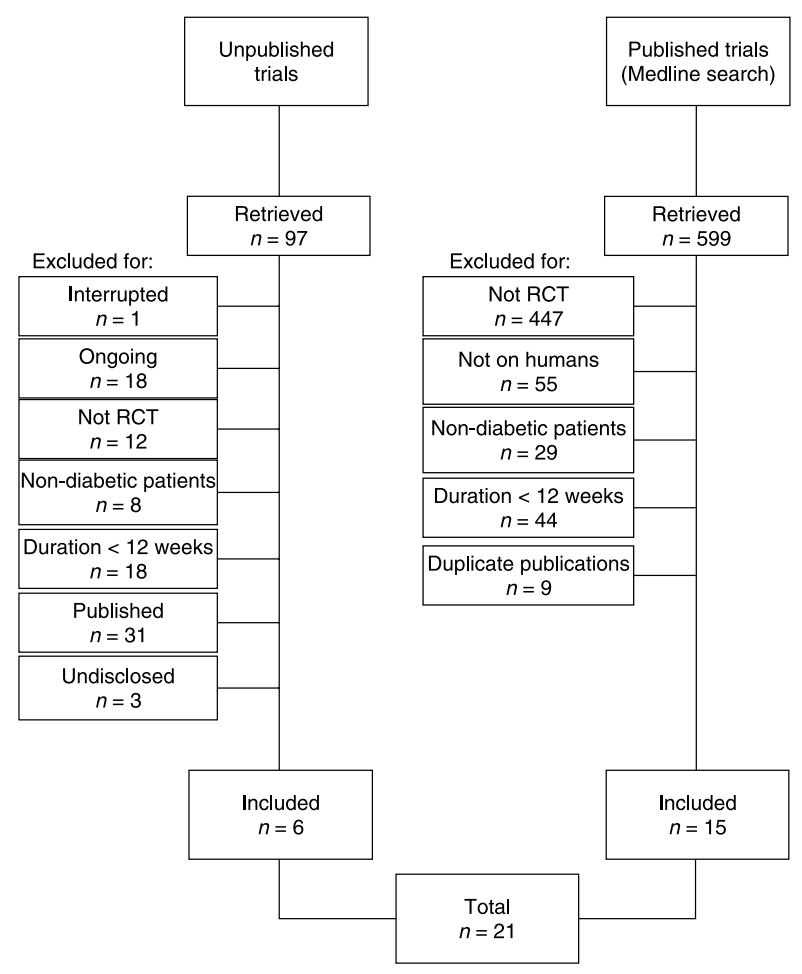

Figure 1 Trial flow diagram. RCT, randomized clinical trial. 
A further Cochrane search yielded 44 hits, out of which four were not randomized clinical trials, seven were duplicate publications, one was a trial performed in non-diabetic subjects and 19 were short-term trials; the remaining 13 trials had already been identified through Medline. The trial flow is summarized in Fig. 1, and the characteristics of the trials included in the meta-analysis are summarized in Table 1 . Among the trials included, 14 were described in publications on peer-reviewed journals; results of five unpublished trials were disclosed on different websites, or in abstracts from ADA and/or EASD 2008 congresses, while two trials, still unpublished at the time of trial selection, became available in peer-reviewed journals during the process of manuscript preparation. Furthermore, one unpublished trial (CT register 9697) was published during the process of preparation of the manuscript, and included in the meta-analysis (16). Among the 21 trials included in the analysis enrolling 8482 patients (5429 with GLP-1 receptor agonists and 3053 with active comparators or placebo), 12 were placebo-controlled and six were active comparator studies; the remaining three studies had two comparator arms, versus placebo and active drugs. Furthermore, three completed unpublished trials, the results of which were undisclosed, could be identified; for one of those (NCT00381342), results were published during the revision of the manuscript and could be included in the analysis, The remaining two trials (NCT00375492 and NCT00313001) explored the effect of exenatide bis in die (b.i.d.) for 24 weeks versus placebo (NCT00375492) or insulin (NCT0031 3001), in combination with sulphonylureas and/or metformin (NCT00375492 and NCT00313001). The number of patients planned was 190 and 540 for NCT00375492 and NCT00313001 respectively.

In order to retrieve undisclosed data, an attempt was made at reaching through email the principal investigators of 14 of the studies included in the analysis. Out of the 14 requests, eight remained unanswered, despite the correct delivery of the e-mail message (and the fact that the message had actually been read in most cases). Out of the remaining six investigators, four clarified that the request for the disclosure of data had to be addressed to the sponsor, while two declined the invitation for other reasons. The sponsors were addressed the same request, which remained unanswered. Therefore, this attempt did not allow the retrieval of any additional information.

\section{Publication bias and heterogeneity}

Considering $\mathrm{HbAlc}$ as the main outcome variable, Begg and Mazumdar rank correlation test was applied to verify publication/disclosure bias. Kendall's tau was

Table 1 Characteristics of the studies included in the meta-analysis.

\begin{tabular}{|c|c|c|c|c|c|c|c|}
\hline $\begin{array}{l}\text { Study } \\
\text { (references) }\end{array}$ & Dose & Comparator & Add on to & Randomization & Blinding & Drop-out & Intention-to-treat \\
\hline \multicolumn{8}{|l|}{ GLP-1 analogues } \\
\hline \multirow{3}{*}{$\begin{array}{l}\text { Liraglutide } \\
\quad \text { Madsbad (9) }\end{array}$} & $\mathrm{mg} / \mathrm{die}$ & & & & & & \\
\hline & $0.045-0.75$ & Glimepiride & None & NA & OL & $A$ & Yes \\
\hline & $0.045-0.75$ & Placebo & None & NA & OL & A & Yes \\
\hline Vilsboll (3) & $0.65-1.90$ & Placebo & None & NA & NA & $A$ & Yes \\
\hline Seino (10) & $0.1-0.9$ & Placebo & None & A & A & A & Yes \\
\hline Feinglos (8) & $0.045-0.75$ & Metformin & None & NA & NA & $A$ & No \\
\hline Garber (22) & $1.2-1.8$ & Glimepiride & None & A & A & A & Yes \\
\hline \multirow[t]{2}{*}{ Nauck (23) } & $1.2-1.8$ & Placebo & Metformin & A & A & A & Yes \\
\hline & & Glimepiride & Metformin & A & A & A & Yes \\
\hline LEAD-1 & $1.2-1.8$ & Placebo & SU & - & - & - & Yes \\
\hline LEAD-4 & $1.2-1.8$ & Placebo & TZD + Met & - & - & - & Yes \\
\hline \multirow[t]{2}{*}{ LEAD-5 } & 1.8 & Placebo & SU+Met & - & - & - & Yes \\
\hline & 1.8 & Glargine & $\mathrm{SU}+\mathrm{Met}$ & - & - & - & Yes \\
\hline \multicolumn{8}{|l|}{ Exenatide } \\
\hline Davis (24) & 20 & Insulin & SU/Met & NA & OL & A & Yes \\
\hline Barnett (25) & 20 & Insulin & SU/Met & $A$ & OL & $A$ & Yes \\
\hline Nauck (26) & 20 & Insulin & $\mathrm{SU}+\mathrm{Met}$ & A & OL & A & Yes \\
\hline Heine (27) & 20 & Insulin & SU+Met & $A$ & OL & $A$ & Yes \\
\hline DeFronzo (28) & $10-20$ & Placebo & Metformin & NA & A & A & Yes \\
\hline Zinman (29) & 20 & Placebo & $\mathrm{TZD} \pm$ Met & A & A & $A$ & Yes \\
\hline Buse (30) & 20 & Placebo & SU & NA & NA & A & Yes \\
\hline Kendall (31) & $10-20$ & Placebo & SU+Met & NA & A & A & Yes \\
\hline CT Register 8683 & $5-10-20$ & Placebo & $S U \pm M e t / T Z D$ & NR & NR & NR & Yes \\
\hline Gao (16) & 20 & Placebo & SU \pm Met & A & A & A & Yes \\
\hline $\mathrm{Kim}(32)^{\mathrm{a}}$ & $0.8-2^{a}$ & Placebo & Met/None & A & A & A & Yes \\
\hline Moretto (33) & $10-20$ & Placebo & None & $A$ & A & $A$ & Yes \\
\hline
\end{tabular}

NA, not adequate; A, adequate; OL, open label; NR, not reported; SU, sulphonylureas; Met, metformin; TZD, thiazolidinediones; - , information not available; \pm , and/or; /, or.

axenatide long-acting release ( $\mathrm{mg} / \mathrm{wk})$. 
$-0.25(P=0.11)$ and $0.14(P=0.36)$ for placeboand active comparator-controlled trials respectively; the corresponding figures for published trials only were $-0.28 \quad(P=0.15)$ and $0.07 \quad(P=0.43)$ respectively.

$\mathrm{I}^{2}$ for HbA1c was 83.6 and 83.2 for placebo- and active comparator-controlled trials respectively (both $P<0.001)$.

\section{Efficacy}

The metabolic effects of GLP-1 receptor agonists observed in clinical trials included in the meta-analysis are summarized in Table 2. The reduction of $\mathrm{HbA1c}$ observed in placebo-controlled trials was significantly greater than that reported in active-comparator studies (test for interaction: $z=4.54, P<0.001)$. The statistical power to detect a $0.5 \%$ difference in $\mathrm{HbA} 1 \mathrm{c}$ at endpoint was $>0.99$ for placebo-controlled trials and for comparative studies versus sulphonylureas and insulin, whereas the corresponding figure for the only one available metformin-controlled trial was 0.65. In placebo-controlled trials, GLP-1 receptor agonists determined a significant reduction of HbA1c (Fig. 2); similar results were obtained when meta-analyzing separately trials with exenatide b.i.d. or liraglutide once a day (o.a.d., Fig. 3). After the exclusion of one trial (10) in which the drug was used at submaximal doses ( $<1$ vs $1.2-1.8 \mathrm{mg} /$ day of the other trials), liraglutide reduced $\mathrm{HbA1c}$ by $-1.0(-1.1,-0.8)$ $(P<0.001)$ in comparison with placebo. Separate analyses were not performed for exenatide long-acting release formulation, due to the small number of available trials. The effects of GLP-1 receptor agonists on $\mathrm{HbA1c}$ were similar in shorter- and longer-term trials (Fig. 3). The reduction of $\mathrm{HbA} 1 \mathrm{c}$ in unpublished trials $(-1.0$ $(-1.1,-0.9) ; P<0.001)$ was similar to that obtained in published trials $(-0.9(-1.1,-0.7) ; P<0.001)$. Furthermore, the effect of GLP-1 receptor agonists on HbA1c in published placebo-controlled trials which did not report satisfactorily randomization procedures $(n=5 ;-0.8(-1.1,-0.5) ; P<0.001)$ was not superior (test for interaction: $z=1.07, P=0.14$ ) to those trials which adequately described this feature $(n=6 ;-1.1 \quad(-1.3,-0.8) ; P<0.001)$; similarly, HbA1c reduction in placebo-controlled trials with inadequate description of allocation concealment $(n=3 ;-0.8(-1.5,-0.1) ; P<0.001)$ was similar $(z=0.13, P=0.023)$ to that of the other, more properly reported, trials $(n=8 ;-1.0(-1.2,-0.8) ; P<0.001)$. The reduction of $\mathrm{HbA1c}$ in placebo controlled trials published before 2005, 2006, 2007, 2008 and 2009 $(n=1,4,4,7$, and 9 respectively) were $-0.1(-0.5$, $0.3), \quad-0.7(-0.9, \quad-0.4), \quad-0.7(-0.9,-0.4)$,

Table 2 Moderators and outcome variables in individual studies included in the meta-analysis.

\begin{tabular}{|c|c|c|c|c|c|c|c|c|c|}
\hline $\begin{array}{l}\text { Study } \\
\text { (references) }\end{array}$ & $\begin{array}{l}\text { Number of } \\
\text { patients } \\
\text { (ID/C) }\end{array}$ & Comparator & $\begin{array}{c}\text { Trial } \\
\text { duration } \\
(w k s)\end{array}$ & $\begin{array}{c}\operatorname{Age}^{\mathrm{a}} \\
(\mathrm{ys})\end{array}$ & $\begin{array}{c}\text { Duration } \\
\text { of DM }{ }^{\mathrm{a}} \\
\text { (ys) }\end{array}$ & $\begin{array}{c}\text { HbA1c } \\
\text { baseline }^{a} \\
(\%)\end{array}$ & $\begin{array}{c}\text { HbA1c } \\
\text { endpoint } \\
(\%, \text { ID/C) }\end{array}$ & $\begin{array}{c}\text { BMI } \\
\text { baseline }^{a} \\
\left(\mathrm{~kg} / \mathrm{m}^{2}\right)\end{array}$ & $\begin{array}{c}\text { BMI } \\
\text { endpoint } \\
\left(\mathrm{kg} / \mathrm{m}^{2}\right)\end{array}$ \\
\hline \multicolumn{10}{|l|}{ Liraglutide } \\
\hline \multirow[t]{2}{*}{ Madsbad (9) } & $135 / 26$ & Glimepiride & 12 & 57 & 4.5 & 7.5 & 7.2/7.2 & 30.4 & NR \\
\hline & $135 / 29$ & Placebo & 12 & 57 & 4.5 & 7.5 & 7.2/7.3 & 30.4 & NR \\
\hline Vilsboll (3) & $123 / 40$ & Placebo & 14 & 55 & 5.0 & 8.3 & 7.0/8.5 & 30.0 & NR \\
\hline Seino (10) & $180 / 46$ & Placebo & 14 & 57 & 8.0 & 8.3 & $7.0 / 8.5$ & 23.9 & 23.6/23.3 \\
\hline Feinglos (8) & $176 / 34$ & Metformin & 12 & 53 & 4.7 & 7.0 & $7.6 / 6.9$ & 34.5 & $34.4 / 33.7$ \\
\hline Garber (22) & $498 / 248$ & Glimepiride & 52 & 53 & 5.4 & 8.3 & 7.3/7.8 & 33.1 & $32.4 / 33.5$ \\
\hline \multirow[t]{2}{*}{ Nauck (23) } & $724 / 121$ & Placebo & 26 & 57 & 7.9 & 8.4 & 7.6/8.6 & 31.0 & $30.2 / 31.1$ \\
\hline & $724 / 242$ & Glimepiride & 26 & 57 & 7.4 & 8.4 & $7.6 / 7.5$ & 31.0 & $30.2 / 31.3$ \\
\hline LEAD-1 & $695 / 115$ & Placebo & 26 & 56 & 7.9 & 8.4 & $7.7 / 8.7$ & 30.0 & $30.1 / 30.0$ \\
\hline LEAD-4 & $356 / 177$ & Placebo & 26 & 55 & 9.2 & 8.5 & 7.0/7.9 & 33.5 & 33.0/33.7 \\
\hline \multirow[t]{2}{*}{ LEAD-5 } & 230/119 & Placebo & 26 & 57 & 9.4 & 8.2 & 7.0/8.1 & 30.5 & $29.9 / 30.4$ \\
\hline & 230/232 & Glargine & 26 & 57 & 9.4 & 8.2 & 7.0/7.2 & 30.5 & 29.9/31.1 \\
\hline \multicolumn{10}{|l|}{ Exenatide } \\
\hline Davis (24) & $33 / 16$ & Insulin & 16 & 53 & 11.0 & 8.1 & 8.4/8.2 & 34.0 & $31.5 / 35.1$ \\
\hline Barnett (25) & $136 / 127$ & Insulin & 16 & 55 & 7.4 & 8.9 & $7.5 / 7.5$ & 31.1 & $30.2 / 32.1$ \\
\hline Nauck (34) & $253 / 248$ & Insulin & 52 & 59 & 9.9 & 8.6 & 7.7/7.6 & 30.4 & $29.7 / 31.3$ \\
\hline Heine (27) & $282 / 267$ & Insulin & 26 & 59 & 9.5 & 8.2 & 7.2/7.1 & 31.3 & $30.6 / 32.0$ \\
\hline DeFronzo (28) & 223/113 & Placebo & 30 & 53 & 5.8 & 8.2 & 7.6/8.3 & 34.0 & $33.2 / 33.9$ \\
\hline Zinman (29) & $121 / 112$ & Placebo & 16 & 56 & 7.7 & 7.9 & $7.0 / 8.0$ & 34.0 & $33.4 / 33.9$ \\
\hline Buse (30) & 248/129 & Placebo & 30 & 55 & 6.3 & 8.6 & 7.9/8.7 & 33.3 & 33.1/33.2 \\
\hline Kendall (31) & $486 / 247$ & Placebo & 30 & 55 & 9.0 & 8.5 & $7.8 / 8.6$ & 34.0 & $32.9 / 33.7$ \\
\hline CT Register 8683 & $111 / 40$ & Placebo & 12 & 61 & 11.8 & NR & NR & 25.1 & NR \\
\hline Gao (16) & 234/232 & Placebo & 16 & NR & NR & 8.3 & $7.3 / 8.1$ & NR & NR \\
\hline $\operatorname{Kim}(32)^{b}$ & $30 / 15$ & Placebo & 15 & 54 & 5.0 & 8.5 & $6.9 / 9.0$ & 36.0 & $34.9 / 36.0$ \\
\hline Moretto (33) & $155 / 78$ & Placebo & 24 & 54 & 2.0 & 7.8 & 7.0/7.6 & 32.0 & $30.4 / 31.4$ \\
\hline
\end{tabular}

ID/C, investigational drug/comparator; DM, diabetes mellitus; wks, weeks; ys, years; BMI, body mass Index; NR, not reported.

${ }^{\mathrm{a}}$ Mean values between ID and $\mathrm{C}$ groups.

${ }^{b}$ Exenatide long-acting release. 


\begin{tabular}{|c|c|c|c|c|c|c|}
\hline Study & $\begin{array}{l}\text { Difference } \\
\text { in means }\end{array}$ & $\begin{array}{l}\text { Standard } \\
\text { error }\end{array}$ & Variance & $\begin{array}{l}\text { Lower } \\
\text { limit }\end{array}$ & $\begin{array}{l}\text { Upper } \\
\text { limit }\end{array}$ & $z$ value \\
\hline Buse (30) & -0.800 & 0.123 & 0.015 & -1.042 & -0.558 & -6.492 \\
\hline Goo (1) & -0.800 & 0.107 & 0.011 & -1.009 & -0.591 & -7.503 \\
\hline DeFronzo (28) & -0.700 & 0.115 & 0.013 & -0.926 & -0.474 & -6.062 \\
\hline Kendall (31) & -0.800 & 0.078 & 0.006 & -0.953 & -0.647 & -10.238 \\
\hline Zinmar & -1.0 & 112 & 0.013 & -1.219 & -0.781 & -8.936 \\
\hline Kim & -2.100 & 0.381 & 0.145 & -2.847 & -1.353 & -5.507 \\
\hline Madsbad (9) & -0.100 & 0.212 & 0.045 & -0.516 & -0.316 & -0.471 \\
\hline Vilsboll (3) & -1.500 & 0.141 & 0.020 & -1.777 & -1.223 & -10.607 \\
\hline Seino $(10)$ & -1.500 & 160 & 0.026 & -1.813 & -1.187 & -9.382 \\
\hline Moretto (33) & -0.600 & 0.154 & 0.024 & -0.902 & -0.298 & -3.897 \\
\hline LEAD-1 & -1.000 & 0.131 & 0.017 & -1.257 & -0.743 & -7.641 \\
\hline \multicolumn{2}{|c|}{ Nauck(LEAD-2) (23)-1.000 } & 0.112 & 0.012 & -1.219 & -0.781 & -8.959 \\
\hline LEAD-4 & -0.900 & 0.108 & 0.012 & -1.111 & -0.689 & -8.363 \\
\hline LEAD-5 & -1.100 & 0.125 & 0.016 & -1.346 & -0.854 & -8.767 \\
\hline Overall & -0.953 & 0.080 & 0.006 & -1.109 & -0.796 & -11.921 \\
\hline
\end{tabular}

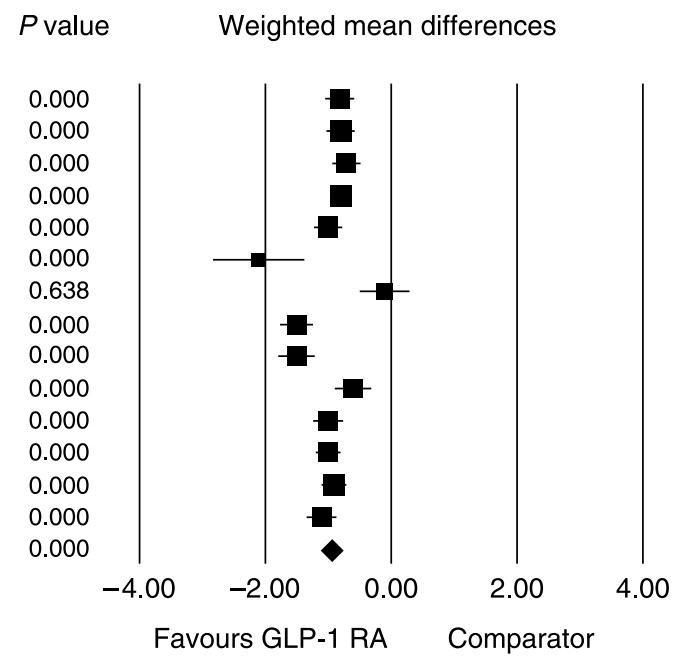

Figure 2 Weighted differences (with $95 \% \mathrm{Cl}$ ) of mean $\mathrm{HbA} 1 \mathrm{c}$ at endpoint across placebo-controlled trials.

$-0.9(-1.2, \quad-0.7), \quad-0.6(-0.9, \quad-0.3) \%, \quad$ with $z$ values of $-0.47,-5.97,-5.97,-6.54$, and -3.90 respectively. When the two trials published in 2009 were added, HbA1c reduction was $-1.0(-1.1,-0.8) \%$, with a $z$ value of -9.00 , while the corresponding figure for all trials (including those still unpublished) were $-1.0(-1.1,-0.8) \%$ and -11.92 .

Trials comparing GLP-1 receptor agonists with other active drugs are summarized in (Fig. 4). GLP-1 receptor agonists were compared with insulin in five trials, showing no significant difference in efficacy on HbA1c (Fig. 3). In comparison with insulin, GLP-1 receptor agonists, which were available only in four exenatide trials, significantly reduced self-monitored $2 \mathrm{~h}$ postprandial glucose after breakfast $(-0.67(-0.56$, $-0.78) \mathrm{mmol} / \mathrm{l} ; \quad P<0.001)$ and dinner $(-0.66$ $(-1.14,-2.73) \mathrm{mmol} / \mathrm{l} ; P<0.001)$, but not lunch (0.19 ( $-0.03,0.42) ; P=0.092)$.

In three trials, a GLP-1 receptor agonist (liraglutide) was compared with sulphonylureas (glimepiride), with no significant difference in HbA1c at endpoint (Fig. 3). Only one trial compared liraglutide with metformin, not allowing any meta-analysis.

\section{Body weight}

GLP-1 receptor agonists led to a significant reduction of BMI, in comparison with placebo $(-0.44(-0.78$, $-0.10) \mathrm{kg} / \mathrm{m}^{2} ; P=0.012 ; 11$ trials). With respect to placebo, difference in endpoint BMI was -0.62 $(-1.14,-0.10) \mathrm{kg} / \mathrm{m}^{2}(P=0.021)$ and -0.30 $(-0.75,0.16) \mathrm{kg} / \mathrm{m}^{2}(P=0.24)$ for exenatide b.i.d. and liraglutide o.a.d. respectively. After the exclusion of one trial (10) in which the drug was used at submaximal doses, the difference in endpoint BMI between liraglutide and placebo was $-0.47(-1.00$, $0.05) \mathrm{kg} / \mathrm{m}^{2}(P=0.077)$.
In comparison with insulin, GLP-1 receptor agonists were associated with a significantly lower endpoint BMI $\left(-1.57(-1.98,-1.15) \mathrm{kg} / \mathrm{m}^{2} ; P<0.001 ; 5\right.$ trials $)$.

\section{Safety: hypoglycaemia}

Data on hypoglycaemic episodes were retrieved in 15 out of 21 trials. Hypoglycaemic episodes were reported by 434 patients ( 325 with investigational drug and 109 with comparator) enrolled in trials with exenatide b.i.d; the corresponding figures for liraglutide ( $n=5$ trials) were 78 and 109 patients with investigational drug,

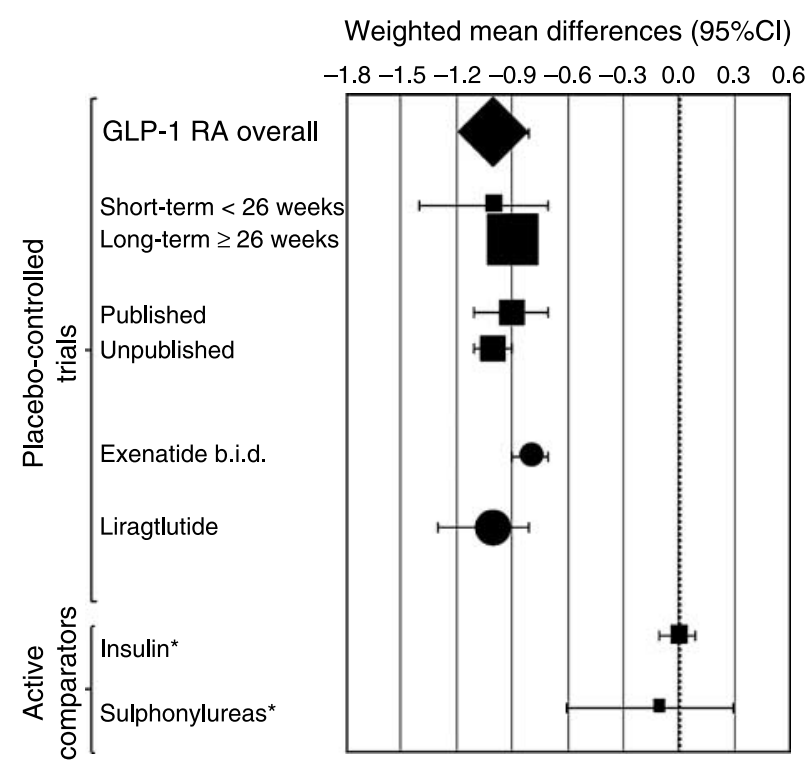

Figure 3 Weighted differences (with $95 \% \mathrm{Cl}$ ) of mean $\mathrm{HbA} 1 \mathrm{c}$ at endpoint. *GLP-1 receptor agonists versus insulin or sulphonylureas. 


$\begin{array}{lcc}\text { Study } & \begin{array}{c}\text { Difference } \\ \text { in means }\end{array} & \begin{array}{c}\text { Standard } \\ \text { error }\end{array} \\ \text { Barnett (25) } & 0.000 & 0.142 \\ \text { Davis (24) } & 0.200 & 0.339 \\ \text { Heine (27) } & 0.100 & 0.085 \\ \text { Nauck (26) } & 0.100 & 0.094 \\ \text { Feinglos (8) } & 0.700 & 0.228 \\ \text { Madsbad (9) } & 0.000 & 0.214 \\ \text { Nauck (23) } & 0.100 & 0.088 \\ \text { Garber (22) } & -0.500 & 0.093 \\ \text { LEAD-5 } & -0.200 & 0.088 \\ \text { Overall } & 0.015 & 0.097\end{array}$

$\begin{array}{crr}\text { Variance } & \begin{array}{c}\text { Lower } \\ \text { limit }\end{array} & \begin{array}{c}\text { Upper } \\ \text { limit }\end{array} \\ 0.020 & -0.279 & 0.279 \\ 0.115 & -0.465 & 0.865 \\ 0.007 & -0.067 & 0.267 \\ 0.009 & -0.084 & 0.284 \\ 0.052 & 0.253 & 1.147 \\ 0.046 & -0.420 & 0.420 \\ 0.008 & -0.072 & 0.272 \\ 0.009 & -0.683 & -0.317 \\ 0.008 & -0.373 & -0.027 \\ 0.009 & -0.175 & 0.206\end{array}$

$z$ value

0.000
0.590
1.171
1.065
3.072
0.000
1.139
-5.361
-2.260
0.159

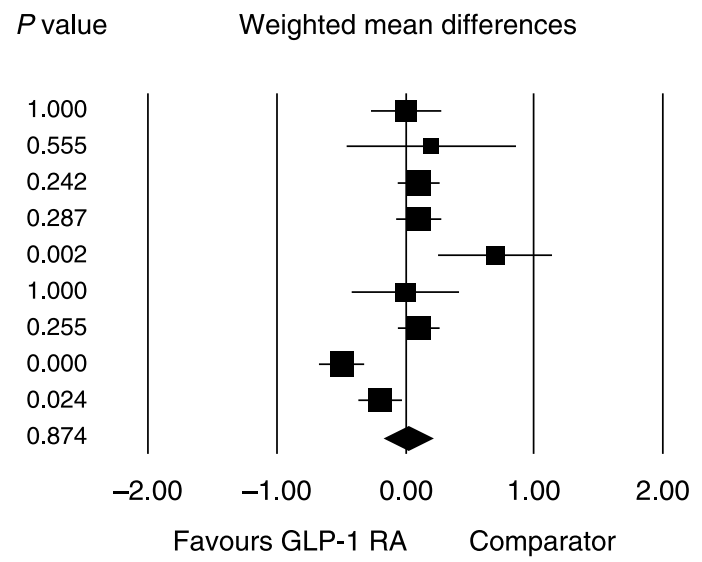
Weighted mean differences

Figure 4 Weighted differences (with $95 \% \mathrm{Cl}$ ) of mean $\mathrm{HbA} 1 \mathrm{c}$ at endpoint across active comparator-controlled trials.

and with comparator respectively. In placebo-controlled trials, exenatide b.i.d. was associated with a significant increase in the proportion of patients experiencing hypoglycaemia (MH-OR 2.92 (1.49, 5.75); $P=0.002)$; however, the excess hypoglycaemic risk associated with exenatide was observed only in trials in which the drug was combined with sulfonylureas (MH-OR 4.62 (1.89, $11.21), P=0.001$ and 1.37 (0.72, 2.63), $P=0.34$, in trials with or without sulphonylureas respectively). When compared with insulin, exenatide b.i.d. was not associated with increased risk for hypoglycaemia (MH-OR $0.61(0.33,1.14), P=0.125)$.

Data on severe hypoglycaemic episodes were retrieved in all trials with exenatide b.i.d., and in eight out of nine trials with liraglutide. In trials with exenatide, severe hypoglycaemic episodes were reported by seven patients enrolled in placebo-controlled trials (five with active drug, two with placebo); in all those trials, exenatide was combined with sulphonylureas. In trials comparing exenatide with insulin, 12 patients experienced severe hypoglycaemia (five with exenatide, seven with insulin); the difference between the groups was not statistically significant (MH-OR $0.74(0.23,2.39) ; P=0.61)$. In the eight trials with liraglutide reporting data on severe hypoglycaemia, only one event was recorded (with liraglutide, in a trial comparing liraglutide with placebo, in combination with sulphonylureas).

\section{Safety: other adverse events}

Information on mortality was available for all trials, except for the unpublished trials with liraglutide $(n=3)$. In trials with GLP-1 receptor agonists only five deaths (two with investigational drugs and three in comparator groups) were observed during the trials included in the meta-analysis.

The incidence of major cardiovascular events was described in 14 out of 21 trials. Twenty-four patients experienced a major cardiovascular event during trials with GLP-1 receptor agonists (Table 3); the MH-OR for cardiovascular events, in comparison with control groups, was $0.99(0.52,1.91)(P=0.98)$. The corresponding figure for placebo-controlled trials $(n=3)$ was $0.46(0.18-1.20), P=0.11$.

Cases of pancreatitis were reported in three and one patients treated with liraglutide and glimepiride respectively. No cases of angioedema were reported. Information on pancreatitis and angioedema was available only for 12 trials. GLP-1 receptor agonists were associated with increased incidence of nausea, vomiting and diarrhoea (Table 4), both in comparison with placebo or insulin (data not shown).

\section{Discussion}

Physicians' knowledge of novel drugs is largely derived from the results of published clinical trials. Conversely, the registration of new compounds is based on the results of trials which may well remain unpublished. The decision to publish a trial is, in most instances, performed by the sponsor, who have a specific interest in pursuing the greater safety and tolerability of the new drug. The reluctance of most investigators to provide undisclosed data, despite a formal request from the authors of this meta-analysis, confirms that concealment of some results is difficult to overcome; however, the retrieval of all available information should always be attempted, although the possibility of including some information of poorer methodological quality should be taken into account.

A major strength of the present study is the inclusion of a substantially greater number of trials in comparison with previous similar meta-analyses (7), thanks to the availability of some recently published or still unpublished, but publicly disclosed (on different websites) studies. The availability of a larger number of studies reduces the impact of the reported heterogeneity of results across trials. The overall efficacy on $\mathrm{HbAlc}$ of GLP-1 agonists in placebo-controlled trials is similar to 
Table 3 Adverse events in individual studies included in the meta-analysis.

\begin{tabular}{|c|c|c|c|c|c|c|c|}
\hline $\begin{array}{l}\text { Study } \\
\text { (references) }\end{array}$ & $\begin{array}{c}\text { Any hypos } \\
(\mathrm{n}, \mathrm{ID} / \mathrm{C})\end{array}$ & $\begin{array}{l}\text { Severe hypos } \\
(n, I D / C)\end{array}$ & $\begin{array}{l}\text { Nausea } \\
(\mathrm{n}, \mathrm{ID} / \mathrm{C})\end{array}$ & $\begin{array}{l}\text { Vomiting } \\
(\mathrm{n}, \mathrm{ID} / \mathrm{C})\end{array}$ & $\begin{array}{c}\text { Diarrhoea } \\
(\mathrm{n}, \mathrm{ID} / \mathrm{C})\end{array}$ & $\begin{array}{c}\text { CVD } \\
(\mathrm{n}, \mathrm{ID} / \mathrm{C})\end{array}$ & $\begin{array}{c}\text { Death } \\
(n, I D / C)\end{array}$ \\
\hline \multicolumn{8}{|l|}{ Liraglutide } \\
\hline \multirow[t]{2}{*}{ Madsbad (9) } & $1 / 4$ & $0 / 0$ & NR & $3 / 1$ & $5 / 0$ & $0 / 0$ & $0 / 0$ \\
\hline & $1 / 0$ & $0 / 0$ & NR & $3 / 0$ & $5 / 0$ & $0 / 0$ & $0 / 0$ \\
\hline Vilsboll (3) & $0 / 0$ & $0 / 0$ & $9 / 1$ & $4 / 0$ & $26 / 5$ & $0 / 0$ & $0 / 0$ \\
\hline Seino (10) & $0 / 0$ & $0 / 0$ & NR & NR & NR & $0 / 0$ & $0 / 0$ \\
\hline Feinglos (8) & $5 / 2$ & $0 / 0$ & $7 / 2$ & $4 / 1$ & NR & NR & $0 / 0$ \\
\hline Garber (22) & $50 / 58$ & $0 / 0$ & $139 / 21$ & $57 / 9$ & $85 / 22$ & NR & $0 / 1$ \\
\hline \multirow[t]{2}{*}{ Nauck (23) } & $22 / 4$ & $0 / 0$ & $290 / 21$ & $44 / 1$ & $88 / 4$ & NR & $0 / 0$ \\
\hline & $22 / 41$ & $0 / 0$ & $290 / 42$ & $44 / 2$ & $88 / 8$ & NR & $0 / 0$ \\
\hline LEAD-1 & NR & $1 / 0$ & $52 / 2$ & NR & NR & NR & NR \\
\hline LEAD-4 & NR & $0 / 0$ & NR & NR & NR & NR & NR \\
\hline LEAD-5 & NR & NR & $32 / 4$ & NR & NR & NR & NR \\
\hline LEAD-5 & NR & NR & $32 / 3$ & NR & NR & NR & NR \\
\hline \multicolumn{8}{|l|}{ Exenatide } \\
\hline Davis (24) & $13 / 6$ & $1 / 0$ & $16 / 2$ & $8 / 1$ & $8 / 0$ & $1 / 0$ & $0 / 0$ \\
\hline Barnett (25) & $20 / 32$ & $0 / 3$ & $58 / 4$ & $13 / 4$ & $4 / 3$ & $0 / 0$ & $0 / 0$ \\
\hline Nauck (34) & NR & $0 / 0$ & $84 / 1$ & $38 / 8$ & $24 / 5$ & $10 / 5$ & $2 / 1$ \\
\hline Heine (27) & NR & $4 / 4$ & $161 / 23$ & $49 / 10$ & $24 / 8$ & $5 / 3$ & $0 / 0$ \\
\hline DeFronzo (28) & $11 / 6$ & $0 / 0$ & $91 / 26$ & $25 / 4$ & $31 / 9$ & NR & $0 / 0$ \\
\hline Zinman (29) & $13 / 8$ & NR & $48 / 17$ & $16 / 1$ & $7 / 3$ & $0 / 0$ & $0 / 0$ \\
\hline Buse (30) & $54 / 4$ & $0 / 0$ & $115 / 9$ & $29 / 3$ & $25 / 5$ & $1 / 2$ & $0 / 0$ \\
\hline Kendall (31) & $114 / 31$ & $1 / 0$ & $213 / 51$ & $69 / 11$ & $67 / 16$ & $7 / 6$ & $0 / 1$ \\
\hline CT Register 8683 & NR & $0 / 0$ & $20 / 0$ & NR & NR & $0 / 0$ & $0 / 0$ \\
\hline Gao (16) & $83 / 21$ & $2 / 1$ & NR & NR & NR & $0 / 2$ & $0 / 0$ \\
\hline $\mathrm{Kim}(32)^{\mathrm{a}}$ & $4 / 0$ & $0 / 0$ & $7 / 1$ & $0 / 0$ & NR & $0 / 0$ & $0 / 0$ \\
\hline Moretto (33) & $7 / 1$ & $0 / 0$ & $12 / 0$ & $6 / 0$ & $2 / 0$ & $0 / 0$ & $0 / 0$ \\
\hline
\end{tabular}

Hypos, hypoglycaemia; ID/C, investigational drug/comparator; CVD, cardiovascular disease; NR, not reported.

${ }^{a}$ Exenatide long acting release.

that reported in a previous meta-analysis (7). However, the greater number of available studies allowed separate analyses of trials using different GLP-1 agonists.

Liraglutide is a novel compound, with similar effects as exenatide, but with more favourable kinetics, allowing a once-daily administration. Despite the fact that several trials with liraglutide have been completed, and included in files for registration submitted to the European authorities, few of these studies have been published so far $(3,8,9)$. Furthermore, some of the published studies $(8,9)$ were performed with submaximal doses of the drug (less than $1 \mathrm{mg} /$ day), while the optimal dose range is $1.2-1.8 \mathrm{mg} /$ day. Therefore, if only published studies were considered, the efficacy of liraglutide could be underestimated (and its tolerability overestimated). The inclusion in the present metaanalysis of several large trials which have already been completed, and disclosed, although still unpublished, allows a more comprehensive assessment of the clinical profile of liraglutide.

Placebo-controlled trials with either exenatide or liraglutide in patient samples of similar characteristics suggest that the efficacy and tolerability of liraglutide should not be inferior to those of exenatide, with the

Table 4 Risk of adverse events with GLP-1 receptor agonists in comparison with control groups.

\begin{tabular}{|c|c|c|c|c|c|}
\hline \multirow[b]{2}{*}{ Adverse event } & \multicolumn{2}{|c|}{ Number of cases } & \multirow[b]{2}{*}{ Number of trials ${ }^{a}$} & \multirow[b]{2}{*}{ MH-OR $(95 \%, \mathrm{Cl})$} & \multirow[b]{2}{*}{$\boldsymbol{P}$} \\
\hline & ID & C & & & \\
\hline \multicolumn{6}{|l|}{ Nausea } \\
\hline GLP-1 receptor agonists & 1354 & 230 & 17 & $3.88(2.79,5.42)$ & $<0.001$ \\
\hline Exenatide b.i.d & 818 & 133 & 10 & $8.38(4.27,16.48)$ & $<0.001$ \\
\hline Liraglutide & 522 & 69 & 6 & $3.48(2.29,5.28)$ & $<0.001$ \\
\hline \multicolumn{6}{|l|}{ Vomiting } \\
\hline GLP-1 receptor agonists & 365 & 56 & 14 & $4.23(2.67,6.13)$ & $<0.001$ \\
\hline Exenatide b.i.d & 253 & 42 & 9 & $4.54(3.24,6.38)$ & $<0.001$ \\
\hline Liraglutide & 108 & 11 & 5 & $4.26(1.01,18.07)$ & 0.049 \\
\hline \multicolumn{6}{|l|}{ Diarrhea } \\
\hline GLP-1 receptor agonists & 396 & 88 & 14 & $2.36(1.67,3.33)$ & $<0.001$ \\
\hline Exenatide b.i.d & 192 & 49 & 9 & $2.56(1.85,3.54)$ & $<0.001$ \\
\hline Liraglutide & 204 & 35 & 5 & $2.36(1.67,3.33)$ & $<0.001$ \\
\hline
\end{tabular}

ID, interventional drug; C, comparator.

${ }^{\text {a }}$ Trials with 0 events or without any information are not included. 
advantage of a once-a-day administration. The only available head-to-head comparison between the two drugs (still unpublished, but disclosed at a congress) showed a small, but significant advantage on $\mathrm{HbA} 1 \mathrm{c}$ for liraglutide over exenatide (17).

Exenatide has a relatively short duration of action; in fact, when administered at breakfast and dinner, it does not seem to reduce satisfactorily the glycaemic peak after lunch. It can be speculated that the longer duration of action of liraglutide, with respect to exenatide, could allow a more accurate control of post-prandial hyperglycaemia throughout the day; however, little data is available on the effects of liraglutide on glycaemic profile to draw any conclusion on this point. It has been reported that liraglutide has a lower immunogenicity than exenatide, with a reduced incidence of antibody formation (18); it is possible that high titres of specific antibodies could interfere with the efficacy of GLP-1 receptor agonists (19).

GLP-1 stimulates insulin secretion and inhibits glucagon production in a glucose-dependent manner, i.e. its effects are blunted when blood glucose reaches the lower limits of the normal range (20). Therefore, GLP-1 receptor agonists are expected to reduce glycaemia with a low hypoglycaemic risk. In fact, monotherapy does not increase the risk of hypoglycaemia in comparison with placebo. Not surprisingly, GLP-1 receptor agonists are associated with a higher incidence of hypoglycaemic episodes when administered in combination with sulphonylureas. However, the hypoglycaemic risk with GLP-1 receptor agonists could be lower than that observed with insulin, although the difference does not reach statistical significance.

The number of cases of severe hypoglycaemia reported in GLP-1 receptor agonist trials is negligible; all cases occurred in patients receiving combined treatment with sulphonylureas.

Among other expected adverse events, nausea, vomiting and diarrhoea are associated with GLP-1 receptor agonists. In this respect, the results of the meta-analysis do not add further information to that reported in individual trials. Interestingly, no case of acute pancreatitis has ever been reported in trials with those drugs.

The introduction of a new class of drugs that are designed for long-term use always raises some concerns about safety during prolonged treatment. The possibility of rare, unexpected serious adverse events, which could not be detected in registration trials, should be considered. Meta-analyses of all available studies, including post-registrative trials, can add some relevant information in this respect. The number of reported deaths in available trials is still very small; however, there is no evidence suggesting an increase in mortality during treatment with GLP-1 receptor agonists. The number of cardiovascular events registered in clinical trials is remarkably greater, although still inadequate to detect minor differences between groups. It should be considered that the duration of the available trials (up to
1 year) is insufficient to detect any effect of treatment (either detrimental or beneficial) on atherogenesis.

The new Consensus algorithm recently issued by ADA/EASD suggests that GLP-1 receptor agonists can be used, in selected cases, as an add-on treatment to metformin (21). Available data summarized in the present meta-analysis suggest that liraglutide could be a valid alternative to exenatide in these same patients.

In conclusion, GLP-1 receptor agonists are effective in reducing $\mathrm{HbA1c}$ and post-prandial glucose. In patients failing to sulphonylureas and/or metformin, GLP-1 receptor agonists are similarly effective as insulin. The safety profile is reassuring, with low hypoglycaemic risk, and no evidence of detrimental effects on cardiovascular disease. GLP-1 receptor agonists, which induce weight loss, produce some gastrointestinal side effects. Available data suggest that the efficacy and tolerability of the novel agent, liraglutide, which is adequate for oncea-day administration, are comparable with those of exenatide b.i.d.

\section{Declaration of interest}

Dr Matteo Monami (MD, PhD) has the following conflicts of interest: 1) speaking fees from Guidotti, Eli Lilly, Merck Sharpe \& Dome, Menarini and Takeda.

2) consultancy fees from Sanofi Aventis and Menarini.

Dr Edoardo Mannucci (MD) has the following conflicts of interest:

1) speaking fees from Abiogen Pharma, Glaxo-Smith-Kline, Guidotti, Eli Lilly, Menarini, Merck Sharp \& Dome, Merck KgA, Novo Nordisk, Novartis, Sanofi Aventis and Takeda.

2) consultancy fees from Novartis, Novo Nordisk and Sanofi Aventis.

3) research grants from Novartis, Novo Nordisk, Sanofi Aventis and Takeda.

Dr Mannucci had full access to all of the data in the study and takes responsibility for the integrity of the data and the accuracy of the data analysis.

Prof. Niccolò Marchionni (MD) has the following conflicts of interest:

1) speaking fees from Glaxo Smith and Kline, Guidotti and Menarini.

2) research grants from Novartis, Novo Nordisk, Sanofi Aventis, Takeda.

\section{Funding}

This research did not receive any specific grant from any funding agency in the public, commercial or not-for-profit sector. Authors did not receive any compensation for their contribution. All authors have seen and approved the final version.

\section{Acknowledgements}

We gratefully acknowledge the technical support of Mrs Rossella Del Bianco in the preparation and revision of the manuscript.

\section{References}

1 Ahren B. GLP-1-based therapy of type 2 diabetes: GLP-1 mimetics and DPP-IV inhibitors. Current Diabetes Reports 20077 340-347.

2 Mikhail N. Incretin mimetics and dipeptidyl peptidase 4 inhibitors in clinical trials for the treatment of type 2 diabetes. Expert Opinion on Investigational Drugs 200817 845-853. 
3 Vilsboll T, Brock B, Perrild H, Levin K, Lervang HH, Kølendorf K, Krarup T, Schmitz O, Zdravkovic M, Le-Thi T \& Madsbad S. Liraglutide, a once-daily human GLP-1 analogue, improves pancreatic B-cell function and arginine-stimulated insulin secretion during hyperglycaemia in patients with Type 2 diabetes mellitus. Diabetic Medicine 200825 152-156.

4 Nathan DM, Buse JB, Davidson MB, Heine RJ, Holman RR, Sherwin R \& Zinman B; Professional Practice Committee, American Diabetes Association; European Association for the Study of Diabetes. Management of hyperglycemia in type 2 diabetes: a consensus algorithm for the initiation and adjustment of therapy: a consensus statement from the American Diabetes Association and the European Association for the Study of Diabetes. Diabetes Care 200629 1963-1972.

5 Inzucchi SE. Incretin enhancers and the evolution of antihyperglycemic therapy in type 2 diabetes. Endocrinology and Metabolism Clinics of North America 200736 2-17.

6 Vilsboll T. Liraglutide: a once-daily GLP-1 analogue for the treatment of type 2 diabetes mellitus. Expert Opinion on Investigational Drugs 200716 231-237.

7 Amori RE, Lau J \& Pittas AG. Efficacy and safety of incretin therapy in type 2 diabetes: systematic review and meta-analysis. Journal of the American Medical Association 2007298 194-206.

8 Feinglos MN, Saad MF, Pi-Sunyer FX, An B \& Santiago O. Effects of liraglutide (NN2211), a long-acting GLP-1 analogue, on glycaemic control and bodyweight in subjects with Type 2 diabetes. Diabetic Medicine 200522 1016-1023.

9 Madsbad S, Schmitz O, Ranstam J, Jakobsen G \& Matthews DR. Improved glycemic control with no weight increase in patients with type 2 diabetes after once-daily treatment with the longacting glucagon-like peptide 1 analog liraglutide (NN2211): a 12-week, double-blind, randomized, controlled trial. Diabetes Care 200427 1335-1342.

10 Seino Y, Rasmussen MF, Zdravkovic M \& Kaku K. Dose-dependent improvement in glycemia with once-daily liraglutide without hypoglycemia or weight gain: a double-blind, randomized, controlled trial in Japanese patients with type 2 diabetes. Diabetes Research and Clinical Practice 200881 161-168.

11 Jadad AR, Moore RA, Carroll D, Jenkinson C, Reynolds DJ, Gavaghan DJ \& McQuay HJ. Assessing the quality of reports of randomized clinical trials: is blinding necessary? Controlled Clinical Trials 199617 1-12.

12 Wood L, Egger M, Gluud LL et al. Empirical evidence of bias in treatment effect estimates in controlled trials with different interventions and outcomes: meta-epidemiological study. BMJ $2008336601-605$.

13 Altman DG \& Bland JM. Interaction revisited: the difference between two estimates. BMJ $2003 \mathbf{3 2 6} 219$.

14 Thorlund K, Devereaux PJ, Wetterslev J, Guyatt G, Ioannidis JP, Thabane L, Gluud LL, Als-Nielsen B \& Gluud C. Can trial sequential monitoring boundaries reduce spurious inferences from metaanalyses? International Journal of Epidemiology 200938 276-286.

15 Wetterslev J, Thorlund K, Brok J \& Gluud C. Trial sequential analysis may establish when firm evidence is reached in cumulative meta-analysis. Journal of Clinical Epidemiology 200861 64-75.

16 Gao Y, Yoon KH, Chuang LM, Mohan V, Ning G, Shah S, Jang HC, Wu TJ, Johns D, Northrup J \& Brodows R. Efficacy and safety of exenatide in patients of Asian descent with type 2 diabetes inadequately controlled with metformin or metformin and a sulphonylurea. Diabetes Research and Clinical Practice 200983 69-76.

17 Blonde L, Rosenstock, Sesti G, Schmidt WE, Montanya E, Brett J, Zychma M \& Buse J. Canadian Diabetes Association 2008 132, A107.

18 Pratley RE \& Gilbert M. Targeting incretins in type 2 diabetes: role of GLP-1 receptor agonists and DPP-4 inhibitors. Review of Diabetic Studies 20085 73-94.

19 Drucker DJ \& Nauck MA. The incretin system: glucagon-like peptide- 1 receptor agonists and dipeptidyl peptidase- 4 inhibitors in type 2 diabetes. Lancet 2006368 1696-1705.

20 Drucker DJ. Enhancing incretin action for the treatment of type 2 diabetes. Diabetes Care 200326 2929-2940.
21 Nathan DM, Buse JB, Davidson MB, Ferrannini E, Holman RR, Sherwin R \& Zinman B; American Diabetes Association; European Association for Study of Diabetes. Medical management of hyperglycemia in type 2 diabetes: a consensus algorithm for the initiation and adjustment of therapy. Diabetes Care 200932 193-203.

22 Garber A, Henry R, Ratner R, Garcia-Hernandez PA, RodriguezPattzi H, Olvera-Alvarez I, Hale PM, Zdravkovic M \& Bode B; LEAD-3 (Mono) Study Group. Liraglutide versus glimepiride monotherapy for type 2 diabetes (LEAD-3 Mono): a randomised, 52-week, phase III, double-blind, parallel-treatment trial. Lancet 2009373 473-481.

23 Nauck M, Frid A, Hermansen K, Shah NS, Tankova T, Mitha IH, Zdravkovic M, Düring M \& Matthews DR; LEAD-2 Study Group. Efficacy and safety comparison of liraglutide, glimepiride, and placebo, all in combination with metformin, in type 2 diabetes: the LEAD (liraglutide effect and action in diabetes)- 2 study. Diabetes Care 2009323 84-90.

24 Davis SN, Johns D, Maggs D, Xu H, Northrup JH \& Brodows RG. Exploring the substitution of exenatide for insulin in patients with type 2 diabetes treated with insulin in combination with oral antidiabetes agents. Diabetes Care 200730 2767-2772.

25 Barnett AH, Burger J, Johns D, Brodows R, Kendall DM, Roberts A \& Trautmann ME. Tolerability and efficacy of exenatide and titrated insulin glargine in adult patients with type 2 diabetes previously uncontrolled with metformin or a sulfonylurea: a multinational, randomized, open-label, two-period, crossover noninferiority trial. Clinical Therapeutics $2007292333-2348$.

26 Nauck MA, Duran S, Kim D, Johns D, Northrup J, Festa A, Brodows R \& Trautmann M. A comparison of twice-daily exenatide and biphasic insulin aspart in patients with type 2 diabetes who were suboptimally controlled with sulfonylurea and metformin: a non-inferiority study. Diabetologia 200750 259-267.

27 Heine RJ, Van Gaal LF, Johns D, Mihm MJ, Widel MH \& Brodows RG. Exenatide versus insulin glargine in patients with suboptimally controlled type 2 diabetes: a randomized trial. Annals of Internal Medicine 2005143 559-569.

28 DeFranzo RA, Ratner RE, Han J, Kim DD, Fineman MS \& Baron AD. Effects of exenatide (exendin-4) on glycemic control and weight over 30 weeks in metformin-treated patients with type 2 diabetes. Diabetes Care 200528 1092-1100.

29 Zinman B, Hoogwerf BJ, Duran GS, Milton DR, Giaconia JM, Kim DD, Trautmann ME \& Brodows RG. The effect of adding exenatide to a thiazolidinedione in suboptimally controlled type 2 diabetes: a randomized trial. Annals of Internal Medicine $2007 \mathbf{1 4 6} 477-485$.

30 Buse JB, Henry RR, Han J, Kim DD, Fineman MS \& Baron AD. Effects of exenatide (exendin-4) on glycemic control over 30 weeks in sulfonylurea-treated patients with type 2 diabetes. Diabetes Care $2004272628-2635$.

31 Kendall DM, Riddle MC, Rosenstock J, Zhuang D, Kim DD, Fineman MS \& Baron AD. Effects of exenatide (exendin-4) on glycemic control over 30 weeks in patients with type 2 diabetes treated with metformin and a sulfonylurea. Diabetes Care 200528 1083-1091.

32 Kim D, MacConell L, Zhuang D, Kothare PA, Trautmann M, Fineman M \& Taylor K. Effects of once-weekly dosing of a longacting release formulation of exenatide on glucose control and body weight in subjects with type 2 diabetes. Diabetes Care 2007 30 1487-1493.

33 Moretto TJ, Milton DR, Ridge TD, Macconell LA, Okerson T, Wolka AM \& Brodows RG. Efficacy and tolerability of exenatide monotherapy over 24 weeks in antidiabetic drug-naive patients with type 2 diabetes: a randomized, double-blind, placebo-controlled, parallel-group study. Clinical Therapeutics 200830 1448-1460.

34 Nauck MA, Duran S, Kim D, Johns D, Northrup J, Festa A, Brodows R \& Trautmann M. A comparison of twice-daily exenatide and biphasic insulin aspart in patients with type 2 diabetes who were suboptimally controlled with sulfonylurea and metformin: a non-inferiority study. Diabetologia 200750 259-267.

Received 4 March 2009

Accepted 9 March 2009 